\title{
The role of US novelty in retention interval effects in single-element taste-aversion learning
}

\author{
W. ROBERT BATSELL, JR., and MICHAEL R. BEST \\ Southern Methodist University, Dallas, Texas
}

\begin{abstract}
Retention interval effects are seen in taste-aversion learning when single-element aversions are significantly weaker $24 \mathrm{~h}$ after conditioning compared with tests at later intervals. This report contains three experiments which suggest that the source of the increased drinking at the 1-day interval is nonassociative interference produced by the novel conditioning episode. In Experiment 1 , a parametric analysis demonstrated that aversion strength increased monotonically over a $30-\mathrm{h}$ period following conditioning, and that by $48 \mathrm{~h}$ after conditioning it was stabilized. In Experiment 2, a single US preexposure was used to reduce the novelty of the US prior to conditioning. As a result, animals preexposed to the US had stronger taste aversions than did nonpreexposed controls at a 1-day retention interval; however, no differences were seen at a 5-day interval. Experiment 3 investigated whether the counterintuitive outcome of Experiment 2 was due to the summation of environment-illness and taste-illness associations at the 1-day test. The results ruled out the summation argument; the US preexposure did not need to be presented in the conditioning context to strengthen the aversion at the 1-day interval. Collectively, these results suggest that the presentation of a surprising US can interfere with the retrieval of the taste-illness association for a short period after conditioning, and that this contributes to the retention interval effect.
\end{abstract}

Conditioned taste aversions are known for their strength and reliability, even following only one conditioning episode (for a review, see Barker, M. R. Best, \& Domjan, 1977; Braveman \& Bronstein, 1985; Brookshire \& Brackbill, 1976). Interestingly, various researchers have reported that taste aversions are paradoxically weak 1 day after conditioning (e.g., Batsell \& M. R. Best, 1992a, 1992b, 1993; Biederman, Milgram, Heighington, Stockman, \& O'Neill, 1974; however, see Kraemer \& Ossenkopp, 1986). For instance, Batsell and M. R. Best (1992a) have demonstrated that single-element taste aversions are stronger 3,5 , or 10 days after conditioning than they are 1 day after conditioning; however, no differences were seen between the groups at the later retention intervals. Thus it appears that for a short period of time following conditioning, some factor is interfering with the animal's retrieval of the taste-illness association. However, this interference then dissipates and strong aversions are observed. Furthermore, in various studies (Batsell \& M. R. Best, 1992a, 1992b) we have determined that this interference is not due to such procedural factors as differential hydration, reinstatement of neophobia/changes

The authors would like to thank Kim Novak for her significant contributions to these experiments and to this report. We would also like to express our gratitude to Anna Dowe and Charles Kallina for their assistance. Portions of this report were presented in November, 1992 at the 33rd annual meeting of the Psychonomic Society in St. Louis. Correspondence should be addressed to Robert Batsell, Department of Psychology, Southern Methodist University, Dallas, TX 75275. in taste preference over time, the aftereffects of illness, or the absence of replacement fluids during the retention interval. Instead, the results suggest that some factor is interfering with the retrieval of the taste-illness association for some period following conditioning.

The results of various experiments (Batsell \& M. R. Best, 1992a, 1992b) implicate novelty-based nonassociative factors as the source of the increased drinking at the 1-day test. This hypothesis-the retrieval disruption hypothesis-is centered on the assumption that the novel conditioning events, specifically the surprisingness of the US, are the source of the subsequent retrieval problems. This hypothesis is based on the findings that surprising USs can produce nonassociative changes in learning and behavior (e.g., Batson \& M. R. Best, 1982; M. R. Best, 1982; Mitchell, Kirschbaum, \& Perry, 1975; Mitchell, Scott, \& Mitchell, 1977; Wagner, Rudy, \& Whitlow, 1973). For example, Batson and M. R. Best (1982) have shown that a US presentation prior to a CS preexposure will eliminate latent inhibition when that $C S$ is later paired with a US. Also, Wagner et al. (1973) reported that the occurrence of a surprising US after a CS-US trial interfered with conditioning to the target CS compared with controls that did not receive the surprising US. These results suggest that a surprising US can interfere with processing for short periods of time following its presentation. These experiments are relevant to the retention interval experiments because if a surprising US can produce short-term interference with the processing of a tar- 
get $\mathrm{CS}$, it is possible that a surprising US may transiently interfere with the retrieval of recently learned events.

If the novelty-based retrieval disruption hypothesis is correct, and nonassociative mechanisms are responsible for the retention interval effects, certain predictions can be made. First, one would expect that the retrieval deficits would dissipate in a systematic fashion following conditioning, and that any lasting effects would not be apparent 3 days after conditioning (Batsell \& M. R. Best, 1992a). Second, if novelty is the key factor in producing the memory deficits, then procedures that can reduce the novelty of the conditioning episode should effectively reduce the interference that causes the retention interval effect. This report describes three experiments that investigated these predictions of the retrieval disruption hypothesis. Experiment 1 investigated the changes in aversion strength over a 3-day period following conditioning. In Experiments 2 and 3, a US preexposure manipulation was utilized to decrease the novelty of the conditioning episode and to evaluate the ramifications of this manipulation for taste aversions at a 1-day retention interval.

\section{EXPERIMENT 1}

Experiment 1 was a parametric analysis of the developing aversion strength across a 72-h interval following conditioning. The purpose was to determine both the duration of the disruptive effect and whether the interference diminishes systematically over time. If this interference is provided by nonassociative factors, one would expect that these effects would be most pronounced immediately after conditioning and that they would dissipate monotonically along with the retention interval. However, if testing occurs while the rats are still experiencing illness, the measurement of these changes may be obscured. For instance, Biederman et al. (1974) tested taste aversions at various retention intervals and found strong suppression 90 min after conditioning, yet these animals were more than likely still experiencing illness. Furthermore, Domjan (1977a, 1977b) has reported decreased fluid consumption following lithium administration shortly after conditioning. To avoid any problems of interpretation due to these extraneous illness effects, the shortest retention interval utilized in this experiment was $18 \mathrm{~h}$, and testing occurred at four other retention intervals also: $24,30,48$, and $72 \mathrm{~h}$.

\section{Method}

Subjects. The subjects were $\mathbf{4 0}$ male albino Holtzman rats, acquired from the Southern Methodist University (SMU) animal colony and ranging from 350 to $460 \mathrm{~g}$ at conditioning. They were housed alone in standard Wahmann cages and had free access to Purina Rat Chow. All rats were maintained on a water-deprivation schedule for 3 weeks prior to conditioning and throughout the experiment. Each rat received a daily water allowance of $40 \mathrm{ml}$ for $20 \mathrm{~min}$. The liquids for all manipulations were presented in the home cages, and all intakes were recorded to the nearest $0.1 \mathrm{ml}$. The animals were assigned to five groups based on their water intakes during a 2-week period prior to experimental manipulations. The five groups $(n=8)$ were differentiated by their retention intervals: Groups R18, R24, R30, R48, and R72 were tested 18, 24, 30, 48, and $72 \mathrm{~h}$ after conditioning, respectively.

Apparatus. The water and other fluids were administered in calibrated 50-ml polypropylene centrifuge tubes fitted with straight stainless-steel drinking tubes. The taste solution was a $0.15 \%$ sodium saccharin solution. A $0.15 \mathrm{M}$ lithium chloride solution was used as the US (12 $\mathrm{mg} \mathrm{LiCl} / \mathrm{kg}$ of body weight).

Procedure. The procedure of this experiment was similar to that of previous retention interval experiments (Batsell \& M. R. Best, 1992a, 1992b). At a given conditioning interval, the specified rats were given 10 -min access to $8 \mathrm{ml}$ of saccharin solution. Fifteen min following the 10 -min $\mathrm{CS}$ period, the rats received the $\mathrm{LiCl}$ injection. Since this experiment utilized short retention intervals, it was difficult to equate hydration across groups. As a result, groups at the shorter retention intervals (i.e., Groups R18, R24, and R30) did not receive any replacement fluids following conditioning, while Groups $R 48$ and $R 72$ received replacement fluids $24 \mathrm{~h}$ after conditioning; however, to control for any possible differences, all groups were limited to $8 \mathrm{ml}$ of fluid (saccharin or water) during the 30 -h period preceding Test Day 1. As a result, all groups should have been at similar hydration levels.

During testing, the rats received $30 \mathrm{ml}$ of saccharin for $20 \mathrm{~min}$. A one-bottle test was used because previous research has shown that it is more effective than a two-bottle method in detecting retention interval differences (Batsell \& M. R. Best, 1993). Testing occurred over 2 consecutive days. Finally, to prevent any residual effects due to differential hydration, all animals received their daily water maintenance $5 \mathrm{~h}$ after testing on Test Day 1 .

Data analysis. In this experiment, a one-way analysis of variance (ANOVA) was employed to assess differences between the five groups. Also, planned comparison $t$ tests were used to investigate specific between-group differences. The statistical significance level was set at .05 .

\section{Results and Discussion}

The animals were assigned to groups matched on their water intakes prior to conditioning. No mean differences were observed, since the groups' averages fell between 20.8 and $20.9 \mathrm{ml}$. All groups drank similar amounts of saccharin solution during conditioning; the group means were: $\mathrm{R} 18=6.8 \mathrm{ml}, \mathrm{R} 24=6.3 \mathrm{ml}, \mathrm{R} 30=6.6 \mathrm{ml}$, $\mathrm{R} 48=6.5 \mathrm{ml}$, and $\mathrm{R} 72=6.5 \mathrm{ml}$.

The mean saccharin intakes on Test Day 1 are shown in Figure 1. It is clear that the strength of the saccharin aversion increased along with the retention interval. On Test Day 1, the groups at the longer retention intervalsGroups R48 and R72-drank the least amount of saccharin, whereas groups at the shorter testing intervals show a systematic decrease across the retention interval. On Test Day 2, the groups at the longer retention intervals continued to drink less saccharin than the other three groups; the group means were: $\mathrm{R} 18=16.4 \mathrm{ml}, \mathrm{R} 24=$ $12.5 \mathrm{ml}, \mathrm{R} 30=12.6 \mathrm{ml}, \mathrm{R} 48=6 \mathrm{ml}$, and $\mathrm{R} 72=$ $7.6 \mathrm{ml}$.

A one-way ANOVA conducted over the saccharin intakes of Test Day 1 revealed a significant group effect $[F(4,45)=4.5]$. The planned comparisons revealed that Groups R48 and R72 drank significantly less saccharin than Groups R24 and R18 and that Group R30 drank significantly less than Group R18. This latter comparison is noteworthy because it further disconfirms relative 


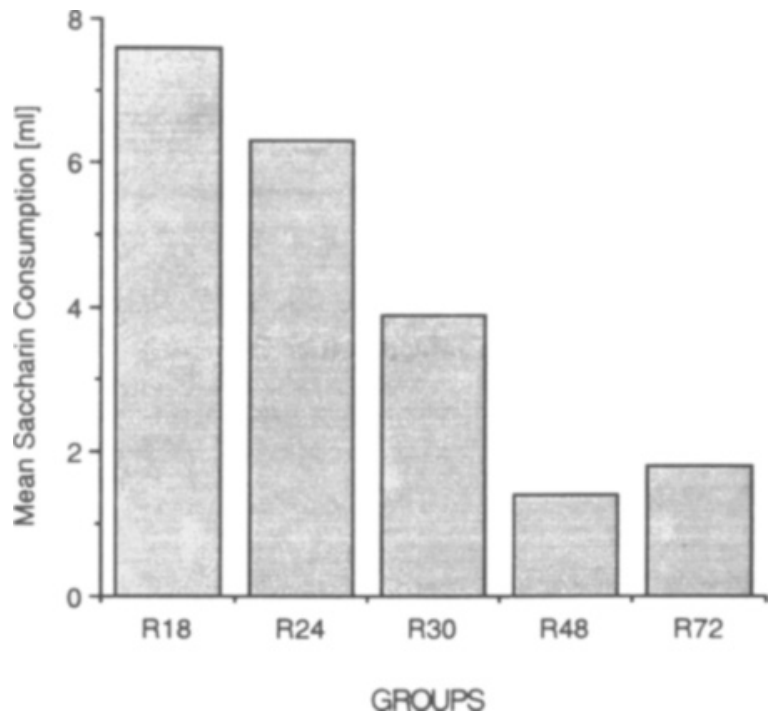

Figure 1. Mean saccharin intake in $\mathrm{ml}$ of Groups R18, R24, R30, R48, and R72 on Test Day 1 of Experiment 1.

hydration as the underlying mechanism of the retention interval effect. None of the groups with the short retention intervals (i.e., R18, R24, and R30) received water during the retention interval. As a result, group differences in relative hydration might be expected to oppose the retention interval differences. This interpretation would only be valid if Group R30 drank more saccharin than Group R18; however, the opposite occurred. This confirms previous findings that differential hydration does not play a role in mediating the retention interval effect (Batsell \& M. R. Best, 1992a, 1992b).

The one-way ANOVA performed over the intakes of Test Day 2 yielded similar results; again, the group effect was significant $[F(4,45)=7.5]$. On this second test day, the planned comparisons revealed that Groups R72 and R48 drank significantly less saccharin solution than Groups R18, R24, and R30. No other between-group comparisons were significant.

In Experiment 1, the pattern of developing aversion strength was examined over a 72 -h period following conditioning in a familiar environment. The rats tested at the shortest retention interval (i.e., $18 \mathrm{~h}$ ) had the weakest saccharin aversion, and the taste aversion increased in strength as the retention interval increased to $48 \mathrm{~h}^{1}{ }^{1}$ Thus, the interference responsible for the retention interval effect dissipates gradually, and has disappeared by $30-48 \mathrm{~h}$ following conditioning. As such, the results of Experiment 1 are straightforward in showing that taste aversions tested during a 30-h period following conditioning are weaker than those tested 2 or more days after conditioning. These results are easily explained by nonassociative retrieval disruption. Following the novel conditioning episode, the rat's ability to completely retrieve the tasteillness association was diminished. However, this retrieval disruption had subsided by the 48-h test, when the tasteillness association was manifested.

As stated earlier, the retrieval disruption hypothesis is based on the premise that US novelty is an important contributor to the interference at short retention intervals. If this is the case, then procedures such as US preexposure that reduce the surprisingness of the US should reduce the retrieval deficits present at short retention intervals. According to the retrieval disruption hypothesis, a single US preexposure will reduce the novelty of the US but not its ability to establish an association between the taste and illness. If so, animals preexposed to the US and then tested following a 1-day retention interval should have stronger aversions than nonpreexposed controls.

This prediction of the retrieval disruption hypothesis may seem counterintuitive, since most reports of US preexposure effects emphasize the deleterious effect of this procedure on conditioning (e.g., Brookshire \& Brackbill, 1976; Cannon, Berman, Baker, \& Atkinson, 1975; Klein et al., 1987; Mikulka, Leard, \& Klein, 1977; Riley, Jacobs, \& LoLordo, 1976; Suarez \& Barker, 1976). This effect has been commonly referred to as the durable US preexposure effect, and it typically occurs following multiple US preexposures. On the other hand, a single US preexposure will only decrease the magnitude of conditioning if it is presented a few hours before conditioning. This has been called the proximal US preexposure effect (M. R. Best, 1982; M. R. Best \& Domjan, 1979; Cannon et al., 1975; Domjan, 1978; Domjan \& M. R. Best, 1977,1980 ). In the proximal US preexposure effect, groups that received a single US presentation within $24 \mathrm{~h}$ of conditioning, for instance, showed weaker taste aversions than nonpreexposed controls. This is not surprising, since the illness episode retards processing of the CS-US association or processing of the taste (M. R. Best, 1982). However, if a single US preexposure occurs more than $24 \mathrm{~h}$ before conditioning, it does not attenuate conditioning (e.g., M. R. Best, 1982; Cannon et al., 1975; Domjan \& M. R. Best, 1980).

Furthermore, the use of a US preexposure manipulation should provide another way to assess the efficacy of an associative account of the retention interval effect, namely, the retrieval competition hypothesis (Batsell \& M. R. Best, 1992b). This hypothesis is based on the assumption that two associations are formed during conditioning. The first is formed between taste and illness, whereas the second is formed between the environment and illness. When testing occurs at short retention intervals, the context-illness association competes with the retrieval of the taste-illness association. Because the animals' exposure to the conditioning environment following conditioning is limited when the test occurs after the short retention interval, maximum retrieval competition should be present and should result in a weaker taste aversion. As the retention interval increases, so does the animals' exposure to the conditioning environment. As a result, the context-illness association should extinguish and less retrieval interference would be present to suppress the taste-illness association. This idea is conceptually sim- 
ilar to the "comparator hypothesis," which is based on the premise that the conditioned response is determined by the comparisons of the current associative strengths of the CS and any other stimuli that were present at conditioning (e.g., Kasprow, Schachtman, \& Miller, 1987; Matzel, Schachtman, \& Miller, 1985; Matzel, Shuster, \& Miller, 1987; Miller \& Schachtman, 1985; Schachtman, Brown, Gordon, Catterson, \& Miller, 1987).

If the retrieval competition hypothesis is correct, then an environment-illness association could be formed during the US preexposure manipulation. Since a context-US association can block the formation of the CS-US association (e.g., Batson \& P. J. Best, 1979; Klein et al., 1987), one might predict that the US preexposure manipulation would increase retrieval competition and thus produce weaker taste aversions in the preexposed groups. On the other hand, as detailed earlier, an opposite outcome would support the retrieval disruption hypothesis.

\section{EXPERIMENT 2}

The purpose of Experiment 2 was to determine whether a US preexposure manipulation would have an impact on the retention interval effect. In order to accomplish this, a US preexposure manipulation was combined with variations in retention interval. Two groups were tested 1 day after conditioning and another two groups were tested under the same conditions 5 days after conditioning. Within each of these retention interval groups, one subgroup had received a US preexposure 4 days prior to conditioning and another subgroup had not. It was hypothesized that one of the effects of the US preexposure would be to reduce the novelty of the conditioning episode. If the elevated drinking following short retention intervals is mediated by the novelty of the conditioning episode, this manipulation might yield a stronger taste aversion relative to that of the 1-day control.

\section{Method}

Subjects and Apparatus. Thirty-eight naive male Holtzman rats from the SMU animal colony and weighing between 250 and $450 \mathrm{~g}$ were the subjects. Housing, feeding, subject assignment, and the water deprivation schedule were the same as in Experiment 1. The animals were assigned to four groups based on their water intakes during a 2-week period prior to experimental manipulations. The groups were differentiated by retention interval [ 1 day (1) or 5 days (5)] and US manipulations [US preexposure (P) or control (C)]. Thus, the four groups were: IP $(n=10), 1 \mathrm{C}(n=10)$, PP $(n=$ 9), and 5C $(n=9)$.

Procedure. Table 1 presents the experimental procedures for the four groups, which were preexposed to the US and conditioned on different days, but tested over the same days. Four days before conditioning (i.e., 9 days before testing), Group 5P received an unpaired injection of $\mathrm{LiCl}$. The $\mathrm{LiCl}$ dose used for US preexposure and conditioning was the same as that used in Experiment 1. This manipulation occurred $15 \mathrm{~min}$ after the animals had received their water on that day. Groups $5 \mathrm{C}$ and $5 \mathrm{P}$ were aversively conditioned to saccharin 5 days before testing. For conditioning, an animal received access to $8 \mathrm{ml}$ of saccharin solution for $10 \mathrm{~min}$. Fifteen minutes later, it received an injection of $\mathrm{LiCl}$. While Groups $5 \mathrm{C}$ and $5 P$ were conditioned to saccharin, Group $1 P$ received their US preexposure. One day prior to testing, Groups $1 \mathrm{P}$ and $1 \mathrm{C}$ were aver-
Table 1

US Preexposure and Conditioning Procedures in Experiment 2

\begin{tabular}{|c|c|c|c|c|}
\hline \multirow[b]{2}{*}{ Groups } & \multicolumn{3}{|c|}{ No. of Days Prior to Testing } & \multirow[b]{2}{*}{ Testing } \\
\hline & 9 & 5 & 1 & \\
\hline $5 P$ & $\mathrm{LiCl}$ alone & Saccharin-LiCl & & Sacc \\
\hline $5 \mathrm{C}$ & & Saccharin-LiCl & & Sacch \\
\hline $1 \mathrm{P}$ & & $\mathrm{LiCl}$ alone & Saccharin- $\mathrm{LiCl}$ & Sacchar \\
\hline IC & & & Saccharin-LiCl & Sacchar \\
\hline
\end{tabular}

Note-All experimental manipulations occurred in the familiar home cage.

sively conditioned to saccharin with the same parameters used for the 5-day groups. To ensure that all animals were at equal hydration levels at the first test, the 5-day groups were limited to $8 \mathrm{ml}$ of water, while the 1-day groups received their $8 \mathrm{ml}$ of saccharin. All testing and posttest watering was as in Experiment 1, and all experimental procedures took place in the familiar home cage.

Data analysis. The animals' saccharin intakes for each test day were analyzed separately using a $2 \times 2$ ANOVA with retention interval and US preexposure as factors. Also, planned comparison $t$ tests were conducted to detect the presence of specific betweengroup differences, specifically because differences due to US preexposure were not expected at both retention intervals.

\section{Results and Discussion}

The animals were matched into four groups according to their mean water intakes for a 2-week period preceding experimental manipulations. The group means ranged from 23.3 to $23.4 \mathrm{ml}$. The mean conditioning intakes were: $1 \mathrm{C}=6.6 \mathrm{ml}, 1 \mathrm{P}=6.3 \mathrm{ml}, 5 \mathrm{C}=6.0 \mathrm{ml}, 5 \mathrm{P}=$ $6.0 \mathrm{ml}$.

Figure 2 shows the groups' mean saccharin solution intake on Test Day 1. It is obvious that Group 1C drank more than the other groups. Group 1P drank an intermediate amount and Groups 5C and 5P drank smaller amounts. This pattern of results continued on Test Day 2. The saccharin solution intakes on this test day were: $1 \mathrm{C}=20.9 \mathrm{ml}, 1 \mathrm{P}=16.7 \mathrm{ml}, 5 \mathrm{C}=10.3 \mathrm{ml}$, and $5 \mathrm{P}=$ $10.7 \mathrm{ml}$.

A $2 \times 2$ ANOVA performed over the groups' saccharin intakes on Test Day 1 revealed a significant retention interval effect $[F(1,34)=30.64]$; however, the US preexposure effect $[F(1,34)=3.47]$ and the retention interval $\times$ US preexposure interaction effect $[F(1,34)=2.85]$ did not reach statistical significance. Planned comparisons showed that Group 1C drank significantly more saccharin than the other groups and, in addition, that Group 1P drank significantly more than Groups 5C and 5P. The 5-day groups did not differ significantly from one another.

The ANOVA over the Test Day 2 intakes again yielded a significant retention interval effect $[F(1,34)=23.34]$, but neither the US preexposure effect $[F(1,34)=1.18]$ nor the interaction effect $[F(1,34)=1.76]$ were significant. On this test day, all of the planned comparisons that were significant on Test Day 1 were still significant except for the difference between Groups 1C and 1P.

Many of the results of this experiment confirm previously reported findings. First, Groups 5C and 5P, which were tested 5 days after conditioning, displayed stronger 


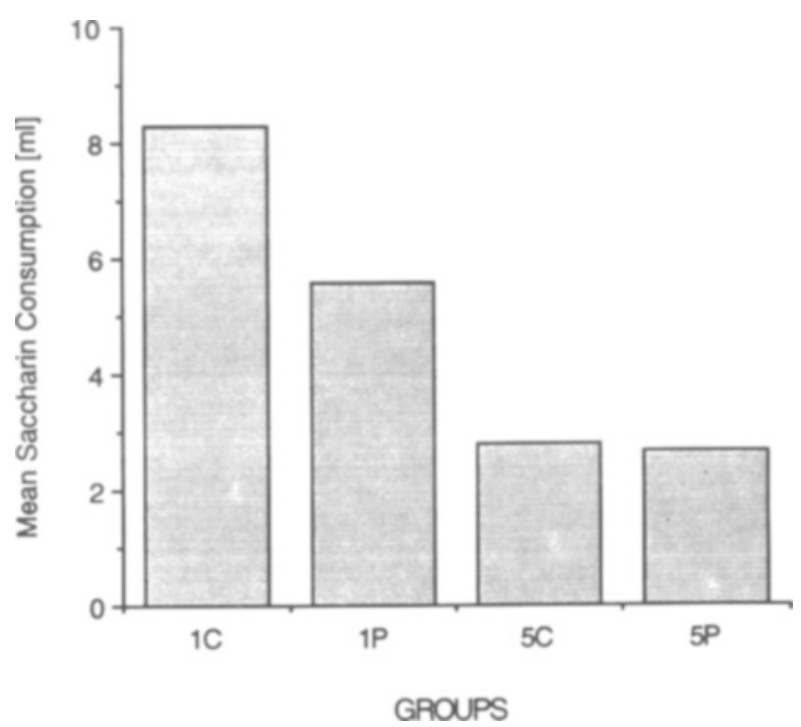

Figure 2. Mean saccharin intake in $\mathrm{ml}$ on Test Day 1 of Experiment 2. Groups $1 P$ and $5 P$ received US preexposure 5 days before saccharin conditioning. Groups $1 C$ and $1 P$ were tested 1 day after conditioning, whereas Groups $5 \mathrm{C}$ and $\mathrm{SP}$ were tested 5 days after conditioning.

aversions than Groups $1 \mathrm{C}$ and $1 \mathrm{P}$, which were tested 1 day after conditioning. These differences are direct replications of the retention interval effect that has been reported previously (e.g., Batsell \& M. R. Best, 1992a, 1992b, 1993; Biederman et al., 1974). Second, at the 5-day interval, a single US preexposure did not alter the strength of the aversion compared with that of a nonpreexposed control. Because Group 5P did not significantly differ from Group 5C, it can be concluded that one US preexposure in a taste-aversion paradigm at a 5-day CTI has no effect. This outcome is not surprising, since others have reported that a single US preexposure will not have an effect on the strength of conditioning unless it occurs close in time to the conditioning sequence (e.g., M. R. Best, 1982; Cannon et al., 1975; Domjan \& M. R. Best, 1980). Furthermore, the results of these 5-day groups show that the single US preexposure did not cause any associative interference at this interval.

More important for the aim of this experiment was the finding that Group 1P drank significantly less than Group 1C on Test Day 1. Initially, this outcome may appear contradictory to previous reports (e.g., Brookshire \& Brackbill, 1976; Cannon et al., 1975; Klein et al., 1987; Suarez \& Barker, 1976); however, this outcome was anticipated by the retrieval disruption hypothesis. According to this hypothesis, reducing the novelty of the US should decrease the disruption that accompanies the initial conditioning episode, and result in a stronger taste aversion. Indeed, the results of the 1-day groups support this prediction. It should be noted, first, that although the US preexposure did appear to strengthen the aversion of Group 1P relative to Group $1 \mathrm{C}$, this difference was only apparent on Test Day 1, and second, that Group 1P still consumed significantly more than both 5-day groups. It is speculated that these results occurred because a single US preexposure may be insufficient to completely reduce the novelty of the illness episode.

An alternative explanation for the observed difference between Groups $1 \mathrm{P}$ and $1 \mathrm{C}$ in Experiment 2 could be based on the contribution of environmental associations. Previous research has shown that repeated illness episodes in a specific environment may lead to an environmentillness association (e.g., Batson \& P. J. Best, 1979; Klein et al., 1987). Although this environment-illness association typically interferes with the formation of the tasteillness association, the presence of an environment-illness association could account for the stronger aversion of Group 1P relative to Group 1C if it happened to summate with the taste-illness association at testing (e.g., Archer, Sjoden, \& Nilsson, 1985; Bonardi, Honey, \& Hall, 1990; Sjoden \& Archer, 1989).

\section{EXPERIMENT 3}

The aim of Experiment 3 was to examine whether associative summation was responsible for the counterintuitive outcome of Experiment 2. To investigate whether environment-illness associations contributed to the stronger aversions at the 1-day interval, some groups were given the US preexposure manipulation in an alternate environment. It was reasoned that animals that were preexposed to the US in an environment other than that used for conditioning could not learn a conditioning environment-illness association during the preexposure trial. Like the 1day control group, the group preexposed in the alternate environment should not have any contributions from environmental associations and would be expected to show a weaker taste aversion than the group that received the US preexposure in the conditioning environment. On the other hand, if the difference between the 1-day groups is due to the reduction of the novelty of the US, all preexposed groups that are tested 1 day after conditioning should have stronger aversions than controls, regardless of the preexposure location.

\section{Method}

Subjects, Apparatus, and Procedure. The subjects in this experiment were 60 male Holtzman rats. These animals were obtained from the SMU animal colony and their weights ranged between 350 and $450 \mathrm{~g}$ at conditioning. All animal housing, feeding, water deprivation, and other procedures were the same as in Experiment 2, and the only differences in the method were related to the use of an additional environment. Prior to any experimental manipulations, all animals received a $24-\mathrm{h}$ preexposure to the alternate environment. This other environment was a $44 \times 24 \times 20 \mathrm{~cm}$ polypropylene mouse breeding cage. Each cage was filled with Sani-Chips (P. J. Murphy Forest Products) and fitted with a steel wire top. These cages were housed in a dimly lit room adjacent to the main vivarium. This environment was chosen because previous research from this laboratory has shown that rats can discriminate between this context and the home cage (e.g., M. R. Best \& Meachum, 1986).

The animals were assigned to one of six groups. Three groups were tested with a 5-day retention interval, whereas the other three groups were tested 1 day after conditioning. At each retention in- 
terval, one group was preexposed to the US in the same environment as that used for conditioning and testing (S), one group was preexposed in an environment different from that used for conditioning and testing (D), and one group was the nonpreexposed control (C). Thus, the six groups were designated as: $5 \mathrm{~S}, 5 \mathrm{D}, 5 \mathrm{C}, 1 \mathrm{~S}$, $1 \mathrm{D}$, and $1 \mathrm{C}$. The experimental procedures for the six groups appear in Table 2. Nine days before testing, the US preexposure manipulation was employed for Groups 5S and 5D. After their daily water regimen, the members of Group 5D were removed from their home cages and placed in a breeding cage for $30 \mathrm{~min}$. The animals received their US preexposure $5 \mathrm{~min}$ into this $30-\mathrm{min}$ period. At the same time, the animals in Group 5S were given their US preexposure in the home cage. At the completion of the 30-min interval, the rats in Group 5D were returned to their home cages. A similar US preexposure was used 5 days before testing for Groups $1 S$ and 1D. These parameters have been used previously in other studies that have evaluated the interaction of US preexposure and environmental effects (e.g., Batson \& P. J. Best, 1979). All conditioning and testing procedures occurred in the home cage and were the same as those utilized in Experiments 1 and 2. Furthermore, the statistical analyses were the same as those performed in Experiment 2 .

\section{Results and Discussion}

The six groups were matched on their water intakes for an 8-day period prior to US preexposure manipulations; all group intakes were $23.3 \mathrm{ml}$. During conditioning, two animals failed to drink more than $3 \mathrm{ml}$ of saccharin and they were, therefore, removed from the experiment. As a result, all groups had 10 members except for Groups $1 \mathrm{C}$ and 1D, which only had 9 members. On the conditioning day, the six groups drank similar amounts of saccharin $(1 \mathrm{~S}=6.1 \mathrm{ml}, 1 \mathrm{D}=6.1 \mathrm{ml}, 1 \mathrm{C}=5.9 \mathrm{ml}, 5 \mathrm{~S}=$ $6.2 \mathrm{ml}, 5 \mathrm{D}=6.5 \mathrm{ml}$, and $5 \mathrm{C}=6.5 \mathrm{ml}$ ).

The mean saccharin intake of the six groups on Test Day 1 is depicted in Figure 3. It is clear that Group 1C animals drank more than the other groups. A similar pattern of results was observed on Test Day 2 (1C = $10.8 \mathrm{ml}, 1 \mathrm{~S}=8.5 \mathrm{ml}, 1 \mathrm{D}=8 \mathrm{ml}, 5 \mathrm{C}=5 \mathrm{ml}, 5 \mathrm{~S}=$ $5.3 \mathrm{ml}$, and $5 \mathrm{D}=6.5 \mathrm{ml}$ ).

A $2 \times 3$ ANOVA using retention interval and US preexposure as factors was performed over the saccharin intakes of Test Day 1 . The analysis yielded a significant retention interval effect $[F(1,52)=12.8]$ and a significant retention interval $\times$ US preexposure interaction $[F(2,52)=3.5]$, but the US preexposure effect was not significant $[F(2,52)=2.2]$. Planned comparisons re-

Table 2

US Preexposure and Conditioning Procedures in Experiment 3

\begin{tabular}{ccccc}
\hline & \multicolumn{3}{c}{ No. of Days Prior to Testing } & \\
\cline { 2 - 5 } Groups & 9 & \multicolumn{1}{c}{5} & \multicolumn{1}{c}{1} & Testing \\
\hline 5S & LiCl alone & Saccharin-LiCl & & Saccharin \\
5D & $\begin{array}{l}\text { LiCl alone } \\
\text { (diff. env.) }\end{array}$ & Saccharin-LiCl & & Saccharin \\
5C & & $\begin{array}{l}\text { Saccharin-LiCl } \\
\text { LiCl alone }\end{array}$ & Saccharin-LiCl & Saccharin \\
1S & & $\begin{array}{l}\text { LiCl alone } \\
\text { (diff. env.) }\end{array}$ & Saccharin-LiCl & Saccharin \\
1D & & & Saccharin-LiCl & Saccharin \\
1C & & &
\end{tabular}

Note-All experimental manipulations occurred in the familiar home cage, except those preexposures designated as different environment (diff. env.).

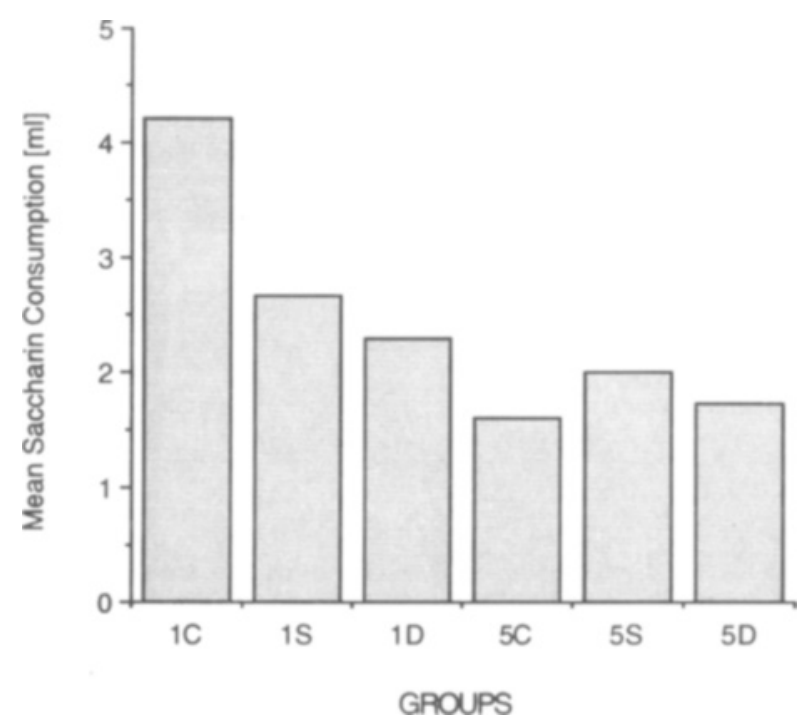

Figure 3. Mean saccharin intake in $\mathrm{ml}$ on Test Day 1 of Experiment 3. Groups $1 S$ and $5 S$ received a single US preexposure in the conditioning/testing environment 4 days before conditioning. Groups 1D and 5D received a US preexposure in an environment different from the conditioning/testing environment 4 days prior to conditioning. Groups $1 \mathrm{C}$ and $5 \mathrm{C}$ had no preexperimental treatments. Groups 1C, 1S, and 1D were tested 1 day after conditioning, whereas Groups 5S, 5D, and 5C were tested 5 days after conditioning.

vealed that Group $1 \mathrm{C}$ drank significantly more than all of the other groups, but no other between-group comparisons were significant. A second $2 \times 3$ ANOVA was performed over the intakes of Test Day 2. A significant retention interval effect was obtained $[F(1,52)=7.8]$, but the US preexposure effect $[F(2,52)<1]$ and the retention interval $\times$ US preexposure interaction $[F(2,52)<1]$ were not significant. The planned comparisons determined that only Groups 5C and 5S drank less than Group 1C on Test Day 2.

The results of Experiment 3 are important for a variety of reasons. First, the results of this experiment replicate the finding of Experiment 2 that a US preexposure strengthens a taste aversion at short retention intervals. Both Groups $1 S$ and $1 D$, which received a US preexposure 4 days before conditioning, had stronger saccharin aversions than Group 1C on Test Day 1. Second, the results are noteworthy because they demonstrate that the stronger aversions observed in Group $1 \mathrm{~S}$ are not due to the summation of an environment-illness association with the taste-illness association. In fact, at neither retention interval did the US preexposure environment modulate the strength of the saccharin aversion. Third, it is notable that although Groups $1 D$ and 5D received their US preexposure in an environment different from that used for conditioning, they did not differ from their counterparts that were preexposed and conditioned in the same environment. As such, it appears that previous experience with illness, regardless of the context, may be sufficient to reduce the novelty of the conditioning episode and prevent retrieval disruption. Finally, no differences were 
seen between the preexposed groups at the 1-day interval (Groups 1S and 1D) and the preexposed groups at the 5-day interval (Groups 5S and 5D). Although differences between similarly treated groups were observed in Experiment 2 (i.e., Group 1P drank more than Group 5P), the absence of these differences in Experiment 3 may suggest that reducing the novelty of the US is sufficient to eliminate the retention interval effect. At the present time, the reason for the differences between Experiments 2 and 3 is not known.

\section{GENERAL DISCUSSION}

These experiments were designed to test the noveltybased retrieval disruption interpretation of the retention interval effect in single-element taste-aversion learning. This was accomplished by examining whether the strength of the aversion increased gradually over time and by manipulating US novelty to produce changes in the retention interval effect. The results of Experiment 1 showed that aversion strength systematically increased over a 48-h period following conditioning and that all deficits in aversion strength had dissipated by the end of that period. In Experiment 2, to reduce the novelty of the US before conditioning, a single US preexposure was given 4 days before conditioning. The preexposed group tested 1 day after conditioning drank significantly less than the nonpreexposed group; however, no differences were observed between the groups tested 5 days after conditioning. Thus, this outcome supports the contention that US novelty contributes to the retention interval effect. The results of Experiment 3 replicated the findings of Experiment 2: Preexposed animals drank significantly less than nonpreexposed animals at short retention intervals, regardless of whether the US preexposure occurred in the conditioning environment or in a different environment. Furthermore, no differences were seen between 1-day groups that were preexposed in different environments 4 days before conditioning, or between any groups tested 5 days after conditioning. The outcome of Experiment 3 demonstrates that the decreased drinking in the preexposed groups at the 1-day interval is not due to the summation of environment-illness and taste-illness associations. The present results suggest that US novelty is an important determinant of the increased drinking seen at the 1-day interval that has been used in recent studies of retention interval differences in taste-aversion experiments (Batsell \& M. R. Best, 1992a, 1992b, 1993).

Numerous studies have documented that single-element taste aversions are weaker when tested within 1 day of conditioning than when tested several days after conditioning (e.g., Batsell \& M. R. Best, 1992a, 1992b, 1993; Biederman et al., 1974). One hypothesis that has been proposed to account for these retention interval differences is the retrieval disruption hypothesis. This hypothesis is based on the notion that a surprising US can interfere with retrieval processes for short periods of time after its presentation. ${ }^{2}$ This is based on previous research that has shown that processing of a target stimulus can be impaired if a surprising US is presented proximally to that target (e.g., Batson \& M. R. Best, 1982; Wagner et al., 1973). In the present research, Experiments 2 and 3 tested the notion that reducing US surprisingness may improve retrieval. Moreover, it was argued that if the surprisingness of the US is crucial to interfering with the retrieval of the taste-illness association, then reducing US novelty would facilitate retrieval of the taste-illness association. The results of these experiments support the retrieval disruption hypothesis, since they demonstrate that reducing the novelty of the US prior to conditioning produces stronger taste aversions at short retention intervals. It is important to note that the US preexposure manipulation did not increase the strength of conditioning, but, rather, reduced the disruption that would be present at test to interfere with the retrieval of the taste-illness association. This point is emphasized by the absence of differences at the 5-day interval: When a sufficient amount of time was allowed for diminution of retrieval disruption, equally strong aversions were observed in the US preexposure and control groups. Thus, the present results are in accordance with predictions based on the retrieval disruption hypothesis.

It should be noted that the present results invite an alternative interpretation in terms of disruption of taste processing. This interpretation is theoretically similar to the retrieval disruption hypothesis, since both are anticipated by the same body of research (e.g., Batson \& M. R. Best, 1982; Wagner et al., 1973). In the taste-processing approach, the locus of the disruption from the surprising US is the organism's representation of the taste rather than its representation of the taste-illness association. According to this hypothesis, one of the effects of the surprising US is to alter the rat's perception of the taste for a period of time following conditioning. As a result, the rat may perceive this taste as distinctly different at the 1-day interval than when testing occurs at the 5-day interval, and it will consume significantly more of this flavor at the 1-day test than it would at the later test. However, like retrieval disruption, these nonassociative processing deficits will diminish quickly over time, and strong aversions will be observed at longer retention intervals. At the present time, the evidence from various retention interval experiments does not allow for the unequivocal confirmation of the retrieval disruption hypothesis or the tasteprocessing disruption hypothesis.

The outcome of these experiments bears on the status of other theories offered to account for the retention interval effect. Although we have previously suggested that the aftereffects of illness or dehydration are not solely responsible for the retention interval effect (see Batsell \& M. R. Best, 1992a, 1992b), the present results provide additional evidence that disqualifies these interpretations. First, in Experiment 1, rats tested $30 \mathrm{~h}$ after conditioning had significantly stronger aversions than those tested $18 \mathrm{~h}$ after conditioning. If a dehydration account was accurate, the dehydrating effects of the $\mathrm{LiCl}$ injection and the retention interval should have been compounded to increase saccharin consumption in the $30-\mathrm{h}$ 
group compared with that of the 18-h group. However, this was not the case. Second, in terms of an illness explanation, the finding in Experiment 3 that the saccharin intakes of the preexposed 1-day groups did not differ from those of the 5-day controls indicates that an $\mathrm{LiCl}$ injection administered $24 \mathrm{~h}$ before testing does not increase drinking. Instead, this outcome suggests that an illness experience can occur proximally to testing without increasing test consumption. ${ }^{3}$ Collectively, the present results provide additional evidence against a dehydration account or an aftereffects-of-illness interpretation of the retention interval effect.

In addition, we have previously proposed a retrieval competition hypothesis, which is based upon the interaction of context-illness associations and taste-illness associations, to explain the results of various retention interval experiments (Batsell \& M. R. Best, 1992a, 1992b). The present results suggest that retrieval competition is not the mechanism underlying most past results. Specifically, if the retrieval competition hypothesis were correct, and associations between the context and the US can form following one US presentation, the US preexposure manipulation that was employed in Experiments 2 and 3 should have strengthened the context-illness association in the preexposed groups. If this were the case, previous research suggests that this context-illness association should have blocked the formation of the taste-illness association and produced a weaker taste aversion (e.g., Batson \& P. J. Best, 1979; Dacanay \& Riley, 1982; Klein et al., 1987). Since the opposite result occurred, it appears likely that a context-illness association was not produced. As such, the results from these experiments suggest that the retrieval competition hypothesis is not a viable explanation for this phenomenon.

Finally, the present results have implications for other areas of Pavlovian conditioning. First, in terms of US preexposure, Experiments 2 and 3 demonstrated that a single US preexposure 4 days before conditioning can influence taste-aversion learning. Previously, Cannon et al. (1975) had observed that a US preexposure 4 days before conditioning had no effect on the strength of a conditioned taste aversion. But in Cannon et al. the retention interval was 3 days, and thus the result is not discordant with those of the present experiments, in which tests conducted 1 day after conditioning showed the impact of the US preexposure, whereas tests conducted 5 days after conditioning did not show any effect. Second, the present results are important for other areas of classical conditioning in which changes across a retention interval are examined. One such phenomenon is the release of latent inhibition over time (e.g., Kraemer \& Ossenkopp, 1986; Kraemer \& Roberts, 1984; for a review, see Bouton, 1993). In 1984, Kraemer and Roberts reported that latent inhibition effects that were present at a 1-day retention interval dissipated over a 21-day retention interval. The present results do not contradict the finding that latent inhibition is susceptible to time effects; instead, they clearly show that tests performed 1 day after conditioning are susceptible to misinterpretation. Thus, future investigators who wish to study the retrievability of stimuli across retention intervals are cautioned to schedule their first test at least $48 \mathrm{~h}$ after conditioning. ${ }^{4}$

In conclusion, the present experiments have both practical and theoretical importance for the study of taste aversions across retention intervals. From a practical standpoint, the current results clearly demonstrate that tests should be delayed at least 2 days after conditioning for the full expression of the taste aversion. In terms of theoretical significance, they provide further evidence that the increased drinking at the 1-day interval is a result of the surprising US, and not of retrieval competition. Future research needs to address the generality of this effect of US surprisingness and its implications for the understanding of memorial processes.

\section{REFERENCES}

Archer, T., SJoden, P., \& Nilsson, L. (1985). Contextual control of taste-aversion conditioning and extinction. In P. D. Balsam \& A. Tomie (Eds.), Context and learning (pp. 225-271). Hillsdale, NJ: Erlbaum.

Bakner, L., Strohen, K., Nordeen, M., \& Riccio, D. C. (1991). Postconditioning recovery from the latent inhibition effect in conditioned taste aversion. Physiology \& Behavior, 50, 1269-1272.

Barker, L. M., Best, M. R., \& DoMJAN, M. (Eds.). (1977). Learning mechanisms in food selection. Waco, TX: Baylor University Press.

BATSELl, W. R., JR., \& BEST, M. R. (1992a). Investigation of replacement fluids and retention interval differences in taste-aversion learning. Bulletin of the Psychonomic Society, 30, 414-416.

BAtSELL, W. R., JR., \& Best, M. R. (1992b). Variations in the retention of taste aversions: Evidence for retrieval competition. Animal Learning \& Behavior, 20, 146-159.

Batsell, W. R., JR., \& Best, M. R. (1993). One bottle too many? Method of testing determines the detection of overshadowing and retention of taste aversions. Animal Learning \& Behavior, 21, 154-158.

BAtson, J. D. (1983). Effects of repeated lithium injections on temperature, activity, and flavor conditioning in rats. Animal Learning \& Behavior, 11, 199-204.

BATSON, J. D., \& BEST, M. R. (1982). Lithium-mediated disruptions of latent inhibition: Overshadowing by the unconditioned stimulus in flavor conditioning. Learning \& Motivation, 13, 167-184.

BATsON, J. D., \& BEST, P. J. (1979). Drug-preexposure effects in flavoraversion learning: Associative interference by conditioned environmental stimuli. Journal of Experimental Psychology: Animal Behavior Processes, 5, 273-283.

BEST, M. R. (1982). Nonassociative and associative sources of interference with the acquisition of a flavor aversion. In M. L. Commons, R. J. Hernstein, \& A. R. Wagner (Eds.), Quantitative analyses of behavior: Acquisition (pp. 67-85). Cambridge, MA: Ballinger.

Best, M. R., \& Domjan, M. (1979). Characteristics of the lithiummediated proximal US-preexposure effect in flavor-aversion conditioning. Animal Learning \& Behavior, 7, 433-440.

Best, M. R., \& MeachuM, C. L. (1986). The effects of stimulus preexposure on taste-mediated environmental conditioning: Potentiation and overshadowing. Animal Learning \& Behavior, 14, 1-5.

Biederman, G. B., Milgram, N. W., Heighington, G. A., StockMAN, S. M., \& O'Neill, W. (1974). Memory of conditioned food aversion follows a U-shape function in rats. Quarterly Journal of Experimental Psychology, 26, 610-615.

BOAKES, R. A. (1994). The role of injection cues in the development of a taste aversion based on delayed lithium chloride administration. Manuscript submitted for publication.

Bonard, C., Honey, R. C., \& Hall, G. (1990). Context specificity of conditioning in flavor-aversion learning. Animal Learning \& Behavior, 18, 229-237.

Bourne, M. J., Calton, J. L., Gustavson, K. K., \& Schachtman, T. R. (1992). Effects of acute swim stress on LiCl-induced conditioned taste aversions. Physiology \& Behavior, 51, 1227-1234. 
Bouton, M. E. (1993). Context, time, and memory retrieval in the interference paradigms of Pavlovian learning. Psychological Bulletin, 114, 80-99.

Braveman, N. S., \& Bronstein, P. (1985). Annals of the New York Academy of Sciences: Vol. 443. Experimental assessments and clinical applications of conditioned food aversions. New York: New York Academy of Sciences.

BROOKSHIRE, K. H. , \& BRACKBILL, R. M. (1976). Formation and retention of conditioned taste aversions and UCS habituation. Bulletin of the Psychonomic Society, 7, 125-128.

Cannon, D. S., Berman, R. F., Baker, T. B., \& Atkinson, C. A. (1975). Effect of preconditioning unconditioned stimulus experience on learned taste aversions. Journal of Experimental Psychology: Animal Behavior Processes, 104, 270-284.

Dacanay, R. J., \& Riley, A. L. (1982). The UCS preexposure effect in taste aversion learning: Tolerance and blocking are drug specific. Animal Learning \& Behavior, 10, 91-96.

Domjan, M. (1977a). Attenuation and enhancement of neophobia for edible substances. In L. M. Barker, M. R. Best, \& M. Domjan (Eds.), Leaming mechanisms in food selection (pp. 151-180). Waco, TX: Baylor University Press.

Domuan, M. (1977b). Selective suppression of drinking during a limited period following aversive drug treatment in rats. Journal of $E x$ perimental Psychology: Animal Behavior Processes, 3, 66-76.

DomJan, M. (1978). Effects of proximal unconditioned stimulus preexposure on ingestional aversions learned as a result of taste presentation following drug treatment. Animal Learning \& Behavior, 6 , 133-142.

Doman, M., Best, M. R. (1977). Paradoxical effects of proximal unconditioned stimulus preexposure: Interference with and conditioning of a taste aversion. Joumal of Experimental Psychology: Animal Behavior Processes, 3, 310-321.

DOMJAN, M., BEST, M. R. (1980). Interference with ingestional aversion learning produced by preexposure to the unconditioned stimulus: Associative and nonassociative aspects. Learning \& Motivation, $11,522-537$

Kasprow, W. J., Schachtman, T. R., Miller, R. R. (1987). The comparator hypothesis of conditioned response generation: Manifest conditioned excitation and inhibition as a function of relative excitatory strengths of $\mathrm{CS}$ and conditioning context at the time of testing. Journal of Experimental Psychology: Animal Behavior Processes, 13, 395-406.

Klein, S. B., Becker, T., Boyle, D., Krug, D., Underhill, G., \& Mowrer, R. R. (1987). The influence of context and UCS intensity on the UCS preexposure effect in a flavor aversion paradigm. Learning \& Motivation, 18, 356-370.

KRAEMER, P. J., \& OSSENKOPP, K.-P. (1986). The effects of flavor preexposure and test interval on conditioned taste aversions in rats. Bulletin of the Psychonomic Society, 24, 219-221.

Kraemer, P. J., \& Roberts, W. A. (1984). The influence of flavor preexposure and test interval on conditioned taste aversions in the rat. Learning \& Motivation, 15, 259-278.

Matzel, L. D., Schachtman, T. R., \& Miller, R. R. (1985). Recovery of an overshadowed association achieved by extinction of the overshadowing stimulus. Learning \& Motivation, 16, 398-412.

Matzel, L. D., Shuster, K., Miller, R. R. (1987). Covariation in conditioned response strength between stimuli trained in compound. Animal Learning \& Behavior, 15, 439-447.

MikulKa, P. J., LEARD, B., \& KLEIN, S. B. (1977). Illness-alone eXposure as a source of interference with the acquisition and retention of a taste aversion. Journal of Experimental Psychology: Animal Behavior Processes, 3, 189-201.

Miller, R. R., \& Schachtman, T. R. (1985). Conditioning context as an associative baseline: Implications for response generation and conditioned inhibition. In R. R. Miller \& N. E: Spear (Eds.), Information processing in animals: Conditioned inhibition (pp. 51-88). Hillsdale, NJ: Erlbaum.

Mitchell, D., Kirschbaum, E. H., \& Perry, R. L. (1975). Effects of neophobia and habituation on the poison-induced avoidance of exteroceptive stimuli in the rat. Joumal of Experimental Psychology: Animal Behavior Processes, 104, 47-55.

Mitchell, D., ScotT, D. W., \& Mitchell, L. K. (1977). Attenuated and enhanced neophobia in the taste-aversion "delay of reinforcement" effect. Animal Learning \& Behavior, 5, 99-102.

RiLEY, A., JACOBS, W. J., \& LoLoRdo, V. M. (1976). Drug exposure and the acquisition and retention of a conditioned taste aversion. Journal of Comparative \& Physiological Psychology, 90, 799-807.

Schachtman, T. R., Brown, A. M., Gordon, E., Catterson, D., \& Miller, R. R. (1987). Mechanisms underlying retarded emergence of conditioned responding following inhibitory training: Evidence for the comparator hypothesis. Journal of Experimental Psychology: Animal Behavior Processes, 13, 310-322.

SHaw, N. (1986). Disruption of conditioned taste aversion: The effect of ECS after the taste-illness interval. Physiology \& Behavior, 38, 431-434.

Suoden, P., \& Archer, T. (1989). Taste-aversion conditioning: The role of contextual stimuli. In T. Archer \& L. Nilsson (Eds.), Aversion, avoidance, and anxiety (pp. 87-120). Hillsdale, NJ: Erlbaum.

SUAREZ, E. M., B BARKER, L. M. (1976). Effects of water deprivation and prior $\mathrm{LiCl}$ exposure in conditioning taste aversions. Physiology \& Behavior, 17, 555-559.

WAGNeR, A. R., RuDY, J. W., \& Witlow, J. W. (1973). Rehearsal in animal conditioning. Journal of Experimental Psychology, 97, $407-426$.

WILLNER, J. A. (1978). Blocking of a taste aversion by prior pairings of exteroceptive stimuli with illness. Learning \& Motivation, 9, 125-140.

\section{NOTES}

1. It should be acknowledged that the systematic increase in aversion strength observed in Experiment 1 could be interpreted as a consolidation or incubation effect. However, this interpretation is only valid if one assumes that the taste-illness association is not consolidated completely by the $18-\mathrm{h}, 24-\mathrm{h}$, or $30-\mathrm{h}$ tests. This assumption is contradicted by various studies that have presented distractors following taste- $\mathrm{LiCl}$ conditioning. For instance, Bourne, Calton, Gustavson, and Schachtman (1992) have reported that a 5-min swim-stress session imposed $90 \mathrm{~min}$ after conditioning did not impair aversion strength relative to that of controls. Furthermore, Shaw (1986) found similar results when electroconvulsive shock (ECS) was presented at varying intervals $(0$, $5,10,15,30,60$, and $120 \mathrm{~min}$ ) following a sucrose-LiCl pairing. If the ECS was performed more than 15 min after conditioning, no deficits in aversion learning were recorded. These results indicate that the tasteillness association becomes stabilized shortly after conditioning and that the parameters of the present phenomenon make the consolidation/incubation interpretation highly unlikely.

2. Throughout this report, although we have been referring to the surprisingness of the conditioning episode, we have only been manipulating the novelty of the US. As such, it needs to be established that other aspects of the conditioning episode besides the US may be contributing to the retrieval disruption. For instance, the injection cues that accompany the US preexposure manipulation are a potent stimulus that is very novel for the rat. Considering that injection cues can serve as a CS over repeated conditioning trials (Boakes, 1994; Willner, 1978), their impact in the present phenomenon should not be overlooked.

3. In light of these findings, an alternative illness interpretation could be offered which argues that the dehydration produced by the initial $\mathrm{LiCl}$ injection is significantly greater than that produced by subsequent $\mathrm{LiCl}$ injections. However, previous research studying tolerance to $\mathrm{LiCl}$ and its physiological effects has found that rats do not show a rapid shift in tolerance following the initial $\mathrm{LiCl}$ presentation (e.g., Batson, 1983; Suarez \& Barker, 1976). Thus, it appears that the various illness interpretations are inadequate to accommodate the findings of the retention interval experiments.

4. In fact, it should be noted that other investigators have confirmed the dissipation of latent inhibition across a retention interval when the earliest test was performed at a 2-day interval (Bakner, Strohen, Nordeen, \& Riccio, 1991). Since the results of Experiment 1 in our report clearly show that the increased drinking effect would not be present 2 days after conditioning, it can be concluded that the Bakner et al. outcome is not confounded by retrieval disruption factors.

(Manuscript received June 8, 1993; revision accepted for publication November $30,1993$. 